\title{
Karakteristik kualitas hidup pasien dalam menjalani kemoterapi
}

\section{Quality of life caracteristics on patient of cancer patient with chemotherapy}

\author{
Edy Suprayitno $^{1^{*}}$, Doddy Yumam Prasetyo ${ }^{2}$ \\ ${ }^{1,2}$ Program Studi Keperawatan-Program Studi Profesi Ners, Fakultas Ilmu Kesehatan Universitas 'Aisyiyah Yogyakarta, \\ Indonesia, Jl. Siliwangi, Mlangi, Nogotirto, Gamping, Sleman \\ 1edysuprayitno@unisayogya.ac.id*,2dyumamp@gmail.com \\ ${ }^{*}$ Corresponding author
}

Tanggal Submisi: 9 Desember 2020, Tanggal Penerimaan: 5 Januari 2021

\begin{abstract}
Abstrak
Penderita kanker di Indonesia telah mencapai 348.809 orang dengan kematian sebesar 207.210 pada tahun 2018. Berdasarkan Riskesdas 2018 DIY memiliki jumlah penderita kanker mencapai 4,9\%o. Kualitas hidup seseorang dapat dinilai melalui indikator: fungsi fisik, keterbatasan fisik, nyeri yang dialami, kesehatan secara umum, fitalitas, fungsi sosial, keterbatasan emosional, dan kesehatan mental. Tujuan penelitian untuk mengetahui karakteristik kualitas hidup pasien kanker yang menjalani kemoterapi. Metode penelitian deskriptif, teknik pengambilan sampel accidental sampling (30 responden) selama 1 bulan menggunakan kuasioner SF-36 yang dilakukan di RS PKU Muhammadiyah Yogyakarta, Hasil penelitian bahwa dikatakan baik apabila mendapatkan skor rerata $>50$ dan buruk $<50$. Domain kualitas hidup: keterbatasan fisik $(45,83 \%)$, kesehatan secara umum $(51,25 \%)$, keterbatasan emosional $(52,22 \%)$, fungsi fisik $(52,53 \%)$, fungsi sosial $(59,08 \%)$, nyeri tubuh $(64,41 \%)$, vitalitas/daya hidup $(67,25 \%)$ dan kesehatan mental $(83,2 \%)$. Kesimpulannya domain kualitas hidup pasien kanker dalam menjalani kemoterapi adalah baik dan hanya domain keterbatasan fisik katergori buruk.
\end{abstract}

Kata Kunci: kanker; kualitias hidup; kemoterapi; karakteristik

\begin{abstract}
Cancer is the biggest cause of death in the world. Prediction of cancer prevalence in the world will increase 50\% to 50 million in 2020 (WHO, 2000). Based on riskesdas 2018 DIY, the number of cancer patients reached $4.9 \%$. Quality of life of a person can be assessed through indicators: physical function, physical limitations, pain experienced, general health, vitality, social function, emotional limitations, and health. Objective: To determine the characteristics of the quality of life of cancer patients undergoing chemotherapy. Methods: accidental sampling technique of 30 respondents for a month using the SF-36 questionnaire conducted at PKU Muhamamdiyah Hospital of Yogyakarta. the SF-36 questionnaire was eused and obtaining ethical acceptance from KEP 'Aisyiayh University of Yogyakarta: 1153/KEPUNISA/VI/2019. quality of life is good if the score is $>50$ and bad $<50$. Conclusion: The quality of life of cancer patients undergoing chemotherapy is good and only the domain of physical limitations is bad.
\end{abstract}

Keywords: cancer; chemotherapy; characteristics; quality of life 


\section{PENDAHULUAN}

Kanker merupakan pertumbuhan dan perkembangan sel yang tidak normal dan tidak terkontrol (ACS, 2020). Penyakit kanker merupakan penyebab kematian terbesar didunia. Prediksi Prevalensi kanker di dunia meningkat 50\% menjadi 50 juta tahun 2020 (WHO, 2000). Amerika dipredikasi sampai dengan tahun 2020, bahwa jenis kelamin laki-laki mengalami peningkatan $24 \%$ menderita kanker dan perempuan $21 \%$ setiap tahun (CDC, 2020). Sementara itu di Indonesia telah mencapai 348.809 orang dengan kematian sebesar 207.210 pada tahun 2018 (GLOBOCAN 2018, 2020). Berdasarkan Riskesdas 2018 DIY memiliki jumlah penderita kanker mencapai 4,9\%o. Secara nasional populasi laki-laki mencapai 0,7\%o dan perempuan 2,9\%o (Riskesdas, 2018). Sebagian besar (75\%) pasien kanker yang mendatangi pelayanan kesehatan sudah dalam kondisi terminal. Perawatan paliatif berfokus mengatasi stres, nyeri, kelelahan, dan gejala lain yang menyertai kanker dan penyakit serius lainnya, sehingga meningkatkan kualitas hidup pasien (YKI, 2017).

Kondisi seseorang dengan penyakit kanker dapat menyebabkan gangguan dan perubahan pada kualitas hidup. Kualitas hidup adalah penilaian tentang diri sendiri atau orang lain tentang kondisi individu dalam kehidupan yang meliputi aspek budaya, sistem nilai dimana mereka tinggal dan kaitannya dengan tujuan, harapan dan kekhawatiran (Karimi \& Brazier, 2016). Definisi lain yang sederhana adalah persepsi diri sendiri atau kelompok tentang fisik dan Kesehatan mentalnya sepanjang waktu (CDC, 2020). Kualitas hidup seseorang dapat dinilai melalui indikator: fungsi fisik, keterbatasan fisik, nyeri yang dialami, kesehatan secara umum, fitalitas, fungsi sosial, keterbatasa emosional, dan kesehatan mental. Kemoterapi memberikan dampak berupa kelelahan dan gangguan psikososial (Oh \& Cho, 2020). Sebagian besar pasien mangalami ganguan pada fisik, gangguan fisik (Rochmawati et al., 2020). Namun demikian kondisi tersebut tergantung dengan karakter setiap pasien. Seseorang yang memiliki pasangan hidup, fungsi tubuh yang baik, perempuan dan usia, spiritual memiliki kualitas hidup yang baik (Chui et al., 2009), (Bernard et al., 2017).

Namun demikian beberapa peelitian di Indonesia menyimpulkan bahwa penderita penyalit kanker berdampak pada kualitas hidup seperti dampak psikologis: spiritual, dukungan sosial dan kesejahteraan dan merasa sehat tanpa kinsumsi obat (Purwanti, 2013). Penelitian lain menyebutkan bahwa optimisme tidak mempengaruhi kualitas hidup (Nufus \& Tatar, 2017). Kondisi ini menunjukkan bahwa banyak variabl yang mempengaruhi kualitas hidup seseorang termasuk juga karakter kualitas hidup penderita kanker dalam menjalani kemoterapi. Urgensi dari penelitian ini adalah ingin mengetahui karakteristik kualitas hidup pasien yang menjalani kemoterapi. Perbedaan dengan penelitian sebelumnya, pada penelitian ini lebih menekankan pada karakteristis respondennya.

Tujuan penelitian ini adalah untuk mengetahui karakteristik kualitas hidup pasien dalam menjalani kemoterapi berdasarkan indikator kualitas hidup.

\section{METODE PENELITIAN}

Metode penelitian ini menggunakan analisis deskriptif dengan teknik pengambilan sampel accidental sampling yang berjumlah 30 responden selama 1 bulan dengan menggunakan kuasioner $S F-36$ yang dilakukan di RS PKU Muhammadiyah Yogyakarta, penelitian ini mendapatkan layak etik KEP di Universitas 'Aisyiyah Yogyakarta: 1153/KEPUNISA/VI/2019. Dikatakan baik apabila mendapatkan skor rerata $>50$ dan buruk $<50$. 


\section{HASIL DAN PEMBAHASAN}

Berdasarkan hasil penelitian didapatkan data sebagai berikut dan tersaji pada tabel berikut ini:

Tabel 1. Karaketristik responden (N: 30)

\begin{tabular}{|c|c|}
\hline Karakterstik & Frekuensi $(\%)$ \\
\hline \multicolumn{2}{|l|}{ Jenis Kelamin } \\
\hline 1. Perempuan & $24(80 \%)$ \\
\hline 2. Laki-laki & $6 \quad(20 \%)$ \\
\hline Total & $30(100 \%)$ \\
\hline \multicolumn{2}{|l|}{ Jenjang Pendidikan } \\
\hline 1. Tidak Sekolah & $3(10 \%)$ \\
\hline 2. $\mathrm{SD}$ & $5(16,66 \%)$ \\
\hline 3. SMP & $6(20 \%)$ \\
\hline 4. SMA & $12(40 \%)$ \\
\hline 5. PT & $5(16,66 \%)$ \\
\hline Total & $30(100 \%)$ \\
\hline \multicolumn{2}{|l|}{ Jenis Kanker } \\
\hline 1. Kanker Payudara & $18(60 \%)$ \\
\hline 2. Kanker paru-paru & $5(16,7 \%)$ \\
\hline 3. Kanker usus & $4(13,31 \%)$ \\
\hline 4. Kanker prostat & $1(3,33 \%)$ \\
\hline 5. NHL & $1(3,33 \%)$ \\
\hline 6. Melanoma & $1(3,33 \%)$ \\
\hline Total & $30(100 \%)$ \\
\hline
\end{tabular}

Berdasarkan tabel 1 didapatkan hasil bahwa Sebagian besar responden berjenis kelamin perempuan sebesar $80 \%$ dan $20 \%$ berjenis kelamin laki-laki. Pendidikan tertinggi responden adalah SMA dan terrendah adalahtidak sekolah. Jenis kanker yang dialami responden adalah kanker payudara, kanker paru-paru dan kanker usus masing-masing sebesar 60\%, 16,7\%, 13,31\%. Sisanya adalah kanker prostat, NHL dan Melanoma sebesar 3,33\%).

Tabel 2. Derajat Kualitas hidup pasien dalam menjalani kemoterapi (N: 30)

\begin{tabular}{ccc}
\hline Kategori & Jumlah & Persentase (\%) \\
\hline Baik & 20 & 77 \\
Buruk & 10 & 33 \\
\hline
\end{tabular}

Berdasarkan tabel 2 didapatkan bahwa sebagian besar derajat kualitas hidup pasien kanker dalam menjalani kemoterapi adalah baik sebanyak $77 \%$ dan 33\% memiliki derajat kualtas hidup buruk.

Tabel 3. Jabaran kualitas hidup pasien kanker yang menjalani kemoterapi menggunakan SF-36

\begin{tabular}{lcc}
\multicolumn{1}{c}{ FUNGSI FISIK } & $\begin{array}{c}\text { Rata-rata } \\
\text { jawaban asli }\end{array}$ & $\begin{array}{c}\text { Rata-rata } \\
\text { akhhir }\end{array}$ \\
\hline $\begin{array}{l}\text { Kegiatan yang menguras energi, seperti berlari, mengangkat beban berat, ikut } \\
\text { serta dalam olah raga berat. }\end{array}$ & 28,33 \\
$\begin{array}{l}\text { Kegiatan yang tidak terlalu menguras energi, seperti memindahkan meja, } \\
\text { bersepeda dan bekerja di kebun/halaman }\end{array}$ & 44,33 \\
Membawa barang keperluan sehari hari, seperti belanjaan & 50 & $\mathbf{5 5 , 5 3}$ \\
Naik tangga lebih dari 1 tingkat & 56,66 & 61,66 \\
Naik tangga 1 tingkat & 58,33 \\
Membungkuk atau berlutut & 41,66 \\
Berjalan lebih dari 1,6 kilometer &
\end{tabular}




\section{KETERBATASAN FISIK}

Mengurangi jumlah jam yang Anda pakai untuk bekerja dan melakukan kegiatan lain

Tidak mencapai yang Anda inginkan

Terbatas dalam melakukan pekerjaan atau kegiatan lain

Mengalami kesulitan dalam melakukan pekerjaan atau kegiatan lain, misalnya memerlukan waktu lebih lama

\section{NYERI TUBUH}

Nyeri menyebabkan gangguan

50

45,83

Sensasi nyeri

\section{KESEHATAN SECARA UMUM}

Secara umum, bagaimana pendapat anda mengenai kondisi kesehatan Anda Dibandingkan dengan satu tahun yang lalu, bagaimanakah kondisi kesehatan Anda saat ini?

Saya cenderung lebih mudah sakit daripada orang lain

68

Saya sehat seperti orang lain yang saya kenal

Saya berharap kesehatan saya akan memburuk

17,5

Kesehatan saya sempurna

97,5

18,33

\section{VITALITAS}

Apakah Anda merasa penuh semangat?

78,66

Apakah Anda memiliki banyak tenaga?

66

Apakah Anda merasa jenuh?

71,33

Apakah Anda merasa lelah?

55,33

FUNGSI SOSIAL

Emosional mengganggu sosial keluarga, teman 60,83

Emosional mengganggu sosial: berkunjung keluarga, teman

57,33

\section{KETERBATASAN EMOSIONAL}

Mengurangi jumlah jam yang Anda pakai untuk bekerja dan melakukan kegiatan lain

Tidak mencapai yang Anda inginkan

56,66

Tidak dapat melakukan pekerjaan atau kegiatan lain secermat biasanya

56,66

Apakah Anda merasa gelisah?

Apakah Anda merasa putus asa dan kecewa seolah-olah tidak ada orang lain yang dapat membahagiakan Anda?

Apakah Anda merasa tenang dan damai?

Apakah Anda merasa murung dan sedih?

77,33

Apakah Anda merasa bahagia?

Berdasarkan tabel 3 didapatkan bahwa rerata skor domain kualitas hidup pasien kanker yang menjalani kemoterapi dalam kategor baik yaitu komponen vitalitas atau daya hidup, nyeri tubuh, fungsi sosial, fungsi fisik, keterbatasan emosional, kesehatan secara umum. Sedangkan keteratasan fisik memiliki kategori buruk.

Berbagai macam faktor yang mempengaruhi kualitas hidup pasien kanker antara lain faktor-faktor tersebut meliputi: stigma masyarakat kepada pasien, dukungan keluarga (takut 
kehilangan anggota keluarga), dukungan sosial, psikologis (ketakutan aktif dalam masyarakat) akibatnya pasien akan merasa ragu dan takut untuk melakukan aktifitas dan berhubungan sosial (Heydarnejad et al., 2011), depresi, potensial kerusakan kognitif (Chen, Hsiao-Mei; Chen, 2017). Penelitian lain menyebutkan bahwa usia, jenis kelamin, tingkat Pendidikan akan mempengaruhi pemilihan terapi yang akan dilakukan (Shrestha et al., 2019), (Alsayed et al., 2017). Apabila dilihat dari fungsi atau domain kualitas hidup faktor utama yang mempengaruhi kualtas hidup paien kronik adalah adanya perubahan fungsi kognitif dan peran. Kondisi ini mengalami penurunan daya ingat, dan tidak mudah konsentrasi (Ayu Juwita et al., 2019). Selain itu jenis penyakit dan status Kesehatan, (Punta et al., 2019), keluhan fisik (nyeri yang dirasakan,rasa lelah yang tinggi dan jenis kanker juga mempengaruhi kualitas hidup seseorang (Heydarnejad et al., 2011).

\section{A. FUNGSI FISIK}

Fungsi fisik pada kualitas hidup adalah kondisi kemamppuan fisik atau tubuh untuk dapat melakukan aktifitas normal. Faktor yang mempengaruhi fungsi fisik adalah energi/ kelelahan, stamina, nyeri, sakit/ sehat, istirahat (Post, 2014), (Lavdaniti et al., 2019).

Berdasarkan hasil penelitian didapatkan bahwa domain fungsi fisik mendapatkan nilai rerata adalah 55,53. Hal ini menunjukkan bahwa domain fungsi fisik pasien kanker yang menjalani kemoterapi adalah baik. Meskipun demikian masih dapat ditemukan bahwa ada beberapa hal yang masih perlu diperhatikan dan ditingkatkan agar fungsi fisik semain baik. beberapa hal tersebut antara lain: pasein selalu merasa mudah lelah, tidak bisa melakukan olahraga dengan baik, tidak mampu melakukan aktifitas berat dan menguras energi dan berjalan dalam jangka waktu panjang dan jauh. Penelitian lain juga menunjukkan bahwa fungsi fisik berperan dalam kualitas hidup. Juga sebagi sarana untuk melakukan koping terhadap Tindakan yang dlakukan atau didapatkan terhadap penyakit (Owczarek, 2010). Senada dengan penelitian lain, seseorang yang mengalami penyakit kronis akan mengalami gangguan fungsi fisik seperti: kecepatan aktifitas, melakukan kegiatan yang panjang dan lama (Erlandson et al., 2014).

\section{B. KETERBATASAN FISIK}

Keterbatasan fisik pada pasien kemoterapi menunjukkan angka kurang dari 50. Hal ini berarti pasien sangat merasa fisiknya terbatas dan buruk. Keterbatasan fisik yang dialami pasien kanker yang menjalani kemoterapi antara lain ketidakmampuan untuk melakukan perkejaan yang panjang dan lama, tidak mampu menyelesaikan pekerjaan, sangat terbatas dalam melakukan aktifitas. Penelitian lain menyebutkan bahwa penyakit kronik dapat menyebabkan gangguan atau keterbatasan fisik (Kuvalekar et al., 2015).

Penelitian yang dilakukan oleh Tang et.al, 2016 juga menunjukkan bahwa keterbatasan fisik menjadi hal yang sering dialami oleh orang yang menderita penyakit kronik (Tang et al., 2016). Keterbatasan fisik ini terjadi karena adanya rasa lelah dan kekurangan energi (Charalambous \& Kouta, 2016). Seseorang dengan kondisi yang mengalami keterbatasan fisik harus segara diatasi untuk meningkatkan kualitas hidup pasien dengan cara memberikan motivasi dan dukungan kepada pasein oleh keluarga pasien (Chagani et al., 2017). Disamping itu keterbatasan fisik juga akan menurunkan kualitas hidup pasien baik secara langsung maupun tidak langsung (Park et al., 2017).

Penelitian ini juga menunjukkan bahwa seluruh pasien kanker yang menjalani kemoterapi menyatakan mengalami keterbatasa fisik untuk melakukan aktifitas.

\section{NYERI TUBUH}


Nyeri kanker merupakan suatu kondisi yang dapat mempangaruhi kualitas hidup seseorang dan perawat harus mampu memberikan asuhan keparawatan yang baik untuk meningktakan derajat kualitas hidup pasien (Rodriguez et al., 2019).

Penelitian ini menunjukkan bahwa selama menjalani perawaan kanker dengan kemoterapi, pasien tidak merasakan nyeri yang dapat menurunkan kualtas hidup pasien. Artinya Pasien tetap merasa nyaman dengan kodisinya saat ini. Sebagian besar penelitina menunjukkan bahwa nyeri sangat berkaitan dengan kaulitas hidup pasien dan sering dialami oleh pasien dan biasanya terjadi pada pasien dengan kondisi stase lanjut (Rodriguez et al., 2019), (Costa et al., 2017), (Mantyh, 2006). Meskipun demikian, penelitian ini menunjukan bahwa pasien yang menjalani kemoterapi dapat mengatasi nyeri dengan baik dan menganggap semua baik-baik saja. Kemungkinan inilah yang menyebabkan nyeri yang dirasakan tidak terlalu diperhatikan oleh pasien.

\section{KESEHATAN SECARA UMUM DAN VITALITAS}

Pasien dengan kanker yang menjalani kemoterapi secara umum memiliki status kesehatan yang baik. Kondisi ini terlihat dari rata-rata skor lebih dari 50. Meskipun demikian ada hal yang harus menjadi perhatian yaitu pasien merasa bahwa setahun terakhir merasa kesehatan semakin menurun dan sebagin kecil merasa bahwa kondisinya jelek. Penelitian lain menunjukkan bahwa kemoterapi dapat menyebabkan penurunan status kesehatan pasien (Nayak et al., 2017). Status kesehatan secara umum membaik disebabkan oleh beberapa faktor antara lain vitalitas penuh semangat, bertenaga dan dan tidak bosan meskipun kadang pasien merasakan adanya kelelahan. Deteksi dini yang cepat juga mempengaruhi vitalitas karena dapat mempersiapkan diri sejak awal (Abegaz et al., 2018). Penelitian menunjukkan vitalitas mempengaruhi kualitas hidup pasien (Folker et al., 2019).

Kesehatan secara umum dan vitalitas dipengaruhi oleh pengalaman seseorang dalam menjalani sakit dan dukungan keluarga (Guérin, 2012). Semakin lama pasien manjalani kemoterapi maka pasien mampu beradaptasi dan mempertahankan kualitas hidup pasien (Moinpour et al., 2017).

\section{E. FUNGSI SOSIAL}

Disisi lain walaupun pasien memiliki fungsi sosial yang baik namun pasien masih ada yang merasakan kondisi sakitnya menganggu pertemanan, hubungan antar keluarga dan aktifitas sosial lain. Penelitian lain menunjukkan bahwa apabila fungsi sosial, Kesehatan secara umum baik maka kualitas hidup seseorang juga akan meningkat (Imran et al., 2019). Faktor lainnya adalah dukungan keluarga dan teman yang baik kepada pasien (Suprayitno; Praseetyo; Untari, 2020)Pendidikan Kesehatan dan tingkat Pendidikan (Tang et al., 2016). Dalam kondisi pasien menjalani kemoterapi harus tetap ada dukungan yang penuh dari keluarga, perawat dan tenaga kesehatan lain (Luszczynska et al., 2013).

\section{F. KETERBATASAN EMOSIONAL DAN KESEHATAN MENTAL}

Penelitian ini menunjukkan bahwa pasien dengan kanker yang menjalani kemoterapi memilki emosional dan kesehatan mental yang baik. Pasien mampu memilih aktifitas yang bisa dilakukan dan tidak dilakukan serta menjaga dan mengatur aktifitasnya sendiri. Selain itu pasien merasa tidak gelisah, bahagia, tenang dan damai. Meskipun demikan beberapa penelitian menunjukkan bahwa seserang dengan penyakit kronis akan mengalami keterbatasan emosional dan gangguan kesehatan mental (Muzzatti et al., 2020). Penelitian lain menyebutkan bahwa ketika seseroang tidak mengalami keterbatasan dalam berbagai hal maka kualitas hidup juga baik (Ness et al., 2008). Hal yang dapat dilakukan untuk 
mencegah terjadinya gangguan emosional dan mental adalah dilakukan pendidikan kesehatan, perawatan psikologis dan mempertahankan emosi dan psikis yang baik (Barre et al., 2018), (Cheng et al., 2016), (Bakan \& Guraskin, 2018).

\section{SIMPULAN}

Penelitian ini menunjukkan bahwa kualitas hidup pasien kanker dalam menjalani kemoterapi adalah baik yaitu fungsi fisik, kondisi nyeri, kesehatan secara umum, vitalitas, fungsi sosial, keterbatasan emosiSonal dan kesehatan mental. Pasien kanker yang menjalani kemoterapi senantiasa harus selalu mendapatkan dukungan dari keluarga, tenaga ksehatan, sosial dan psikologis.

\section{REFERENCE}

Abegaz, T. M., Ayele, A. A., \& Gebresillassie, B. M. (2018). Health Related Quality of Life of Cancer Patients in Ethiopia. Journal of Oncology, 2018. https://doi.org/10.1155/2018/1467595

ACS. (2020). American Cancer Society. Cancer Facts \& Figures 2020. In American Cancer Society (pp.

$1-52)$. http://www.cancer.org/acs/groups/content/@nho/documents/document/caff2007pwsecur edpdf.pdf

Alsayed, N. S., Sereika, S. M., Albrecht, S. A., Terry, M. A., \& Erlen, J. A. (2017). Testing a model of health-related quality of life in women living with HIV infection. Quality of Life Research: An International Journal of Quality of Life Aspects of Treatment, Care and Rehabilitation, 26(3), 655-663. https://doi.org/10.1007/s11136-016-1482-4

Ayu Juwita, D., Almahdy, A., \& Afdila, R. (2019). Penilaian Kualitas Hidup Terkait Kesehatan Pasien Kanker Payudara di RSUP dr. M. Djamil Padang, Indonesia. JURNAL ILMU KEFARMASIAN INDONESIA, 17, 114. https://doi.org/10.35814/jifi.v17i1.682

Bakan, A., \& GURAKSIN, A. (2018). FACTORS AFFECTING QUALITY OF LIFE AND LEVEL OF SOCIAL SUPPORT IN CANCER PATIENTS. Belitung Nursing Journal, 3. https://doi.org/10.33546/bnj.48

Barre, P. V., Padmaja, G., Rana, S., \& Tiamongla. (2018). Stress and Quality of Life in Cancer Patients: Medical and Psychological Intervention. Indian Journal of Psychological Medicine, 40(3), 232-238. https://doi.org/10.4103/IJPSYM.IJPSYM_512_17

Bernard, M., Strasser, F., Gamondi, C., Braunschweig, G., Forster, M., Kaspers-Elekes, K., Walther Veri, S., Borasio, G. D., Pralong, G., Pralong, J., Marthy, S., Soloni, C., Bisi, C., \& Magaya, N. K. (2017). Relationship Between Spirituality, Meaning in Life, Psychological Distress, Wish for Hastened Death, and Their Influence on Quality of Life in Palliative Care Patients. Journal of Pain and Symptom Management, 54(4), 514-522. https://doi.org/10.1016/j.jpainsymman.2017.07.019

CDC. (2020). Expected New Cancer Cases and Deaths in 2020. CDC.

Chagani, P., Parpio, Y., Gul, R., \& Jabbar, A. (2017). Quality of life and its determinants in adult cancer patients undergoing chemotherapy treatment in Pakistan. Asia-Pacific 
Journal of Oncology Nursing, 4(2), 140. https://doi.org/10.4103/2347-5625.204499

Charalambous, A., \& Kouta, C. (2016). Cancer Related Fatigue and Quality of Life in Patients with Advanced Prostate Cancer Undergoing Chemotherapy. BioMed Research International, 2016. https://doi.org/10.1155/2016/3989286

Chen, Hsiao-Mei; Chen, C.-M. (2017). Factors Associated with Quality of Life Among Older Adults with Chronic Disease in Taiwan. International Journal of Gerontology, 12-15.

Cheng, A. S. K., Lau, L. O. C., Ma, Y. N. H., Ngai, R. H., \& Fong, S. S. L. (2016). Impact of Cognitive and Psychological Symptoms on Work Productivity and Quality of Life among Breast Cancer Survivors in Hong Kong. Hong Kong Journal of Occupational Therapy, 28, 15-23. https://doi.org/https://doi.org/10.1016/j.hkjot.2016.11.002

Chui, Y. Y., Kuan, H. Y., Fu, I. C. Y., Liu, R. K. Y., Sham, M. K., \& Lau, K. S. (2009). Factors associated with lower quality of life among patients receiving palliative care. Journal of Advanced Nursing, 65(9), 1860-1871. https://doi.org/https://doi.org/10.1111/j.13652648.2009.05051.x

Costa, W. A., Monteiro, M. N., Queiroz, J. F., \& Gonçalves, A. K. (2017). Pain and quality of life in breast cancer patients. Clinics, 72(12), 758-763. https://doi.org/10.6061/clinics/2017(12)07

Erlandson, K. M., Allshouse, A. A., Jankowski, C. M., Mawhinney, S., Kohrt, W. M., \& Campbell, T. B. (2014). Relationship of physical function and quality of life among persons aging with HIV infection. Aids, 28(13), 1939-1943. https://doi.org/10.1097/QAD.0000000000000384

Folker, A. P., Hegelund, E. R., Mortensen, E. L., Wimmelmann, C. L., \& Flensborg-Madsen, T. (2019). The association between life satisfaction, vitality, self-rated health, and risk of cancer. Quality of Life Research: An International Journal of Quality of Life Aspects of Treatment, Care and Rehabilitation, 28(4), 947-954. https://doi.org/10.1007/s11136018-2083-1

GLOBOCAN 2018. (2020). Indonesia - Global Cancer Observatory. WHO; International Agency for Research on 2018. Https://Gco.Iarc.Fr/Today/Data/Factsheets/Populations/360-Indonesia-Fact-Sheets.Pdf, 256, 1-2. https://gco.iarc.fr/today/data/factsheets/populations/360-indonesia-factsheets.pdf

Guérin, E. (2012). Disentangling vitality, well-being, and quality of life: A conceptual examination emphasizing their similarities and differences with special application in the physical activity domain. Journal of Physical Activity and Health, 9(6), 896-908. https://doi.org/10.1123/jpah.9.6.896

Heydarnejad, M. S., Hassanpour Dehkordi, A., \& Solati Dehkordi, K. (2011). Factors affecting quality of life in cancer patients undergoing chemotherapy. African Health Sciences, $11(2), 266-270$.

Imran, M., Al-Wassia, R., Alkhayyat, S. S., Baig, M., \& Al-Saati, B. A. (2019). Assessment of quality of life (QoL) in breast cancer patients by using EORTC QLQ-C30 and BR-23 
questionnaires: A tertiary care center survey in the western region of Saudi Arabia. PLoS ONE, 14(7), 1-13. https://doi.org/10.1371/journal.pone.0219093

Karimi, M., \& Brazier, J. (2016). Health, Health-Related Quality of Life, and Quality of Life: What is the Difference? PharmacoEconomics, 34(7), 645-649. https://doi.org/10.1007/s40273-016-0389-9

Kuvalekar, K., Kamath, R., Ashok, L., Shetty, B., Mayya, S., \& Chandrasekaran, V. (2015). Quality of Life among Persons with Physical Disability in Udupi Taluk: A Cross Sectional Study. Journal of Family Medicine and Primary Care, 4(1), 69-73. https://doi.org/10.4103/2249-4863.152258

Lavdaniti, M., Owens, D., Liamopoulou, P., Marmara, K., Zioga, E., Mantzanas, M., Evangelidou, E., \& Vlachou, E. (2019). Factors Influencing Quality of Life in Breast Cancer Patients Six Months after the Completion of Chemotherapy. Diseases, 7(1), 26. https://doi.org/10.3390/diseases7010026

Luszczynska, A., Pawłowska, I., Cieslak, R., Knoll, N., \& Scholz, U. (2013). Social support and quality of life among lung cancer patients: A systematic review. Psycho-Oncology, 22. https://doi.org/10.1002/pon.3218

Mantyh, P. W. (2006). Cancer pain and its impact on diagnosis, survival and quality of life. Nature Reviews Neuroscience, 7(10), 797-809. https://doi.org/10.1038/nrn1914

Moinpour, C. M., Unger, J. M., Ganz, P. A., Kornblith, A. B., Gaynor, E. R., Bowers, M. A., Gatti, G. S., Kaminski, M. S., Erba, H. P., Wang, T., Yoon, J., Press, O. W., \& Fisher, R. I. (2017). Seven-year follow-up for energy/vitality outcomes in early stage Hodgkin's disease patients treated with subtotal lymphoid irradiation versus chemotherapy plus radiation: SWOG S9133 and its QOL companion study, S9208. Journal of Cancer Survivorship, 11(1), 32-40. https://doi.org/10.1007/s11764-016-0559-y

Muzzatti, B., Bomben, F., Flaiban, C., Piccinin, M., \& Annunziata, M. A. (2020). Quality of life and psychological distress during cancer: a prospective observational study involving young breast cancer female patients. BMC Cancer, 20(1), 758. https://doi.org/10.1186/s12885-020-07272-8

Nayak, M. G., George, A., Vidyasagar, M. S., Mathew, S., Nayak, S., Nayak, B. S., Shashidhara, Y. N., \& Kamath, A. (2017). Quality of life among cancer patients. Indian Journal of Palliative Care, 23(4), 445-450. https://doi.org/10.4103/IJPC.IJPC_82_17

Ness, K. K., Gurney, J. G., Zeltzer, L. K., Leisenring, W., Mulrooney, D. A., Nathan, P. C., Robison, L. L., \& Mertens, A. C. (2008). The impact of limitations in physical, executive, and emotional function on health-related quality of life among adult survivors of childhood cancer: a report from the Childhood Cancer Survivor Study. Archives of Physical Medicine and Rehabilitation, 89(1), 128-136. https://doi.org/10.1016/j.apmr.2007.08.123

Nufus, F. F., \& Tatar, F. M. (2017). Hubungan Antara Optimisme Dengan Kualitas Hidup Pada Pasien Kanker. Psikoislamedia: Jurnal Psikologi, 2(1), 65. https://doi.org/10.22373/psikoislamedia.v2i1.1825 
Oh, P.-J., \& Cho, J.-R. (2020). Changes in Fatigue, Psychological Distress, and Quality of Life After Chemotherapy in Women with Breast Cancer: A Prospective Study. Cancer Nursing, 43(1). https://journals.lww.com/cancernursingonline/Fulltext/2020/01000/Changes_in_Fatigue, _Psychological_Distress,_and.18.aspx

Owczarek, K. (2010). The concept of quality of life. Acta Neuropsychologica, 8(3), 11-17.

Park, Y.-R., Park, E.-Y., \& Kim, J.-H. (2017). Predicting health-related quality of life in cancer patients receiving chemotherapy: a structural equation approach using the self-control model. BMC Health Services Research, 17(1), 710. https://doi.org/10.1186/s12913-0172675-4

Post, M. W. M. (2014). Definitions of quality of life: What has happened and how to move on. Topics in Spinal Cord Injury Rehabilitation, 20(3), 167-180. https://doi.org/10.1310/sci2003-167

Punta, P., Somrongthong, R., \& Kumar, R. (2019). Factors influencing quality of life (QOL) amongst elderly caregivers of people living with HIV/AIDS in Phayao province, Thailand: A cross-sectional study [version 1; peer review: 2 approved]. F1000Research, 8, 1-11. https://doi.org/10.12688/f1000research.16892.1

Purwanti, F. (2013). Developmental and Clinical Psychology. Identitas Diri Remaja Pada Siswa Kelas Xi Sma Negeri 2 Pemalang Ditinjau Dari Jenis Kelamin, 1(1), 21-27.

Riskesdas. (2018). Hasil Utama Riset Kesehata Dasar (RISKESDAS). Journal of Physics A: Mathematical and Theoretical, 44(8), 1-200. https://doi.org/10.1088/17518113/44/8/085201

Rochmawati, E., Wiksuarini, E., \& Rahmah, R. (2020). Depression and quality of life among cancer patients undergoing chemotherapy. Palliative Medicine in Practice, 14(1), 1-6. https://doi.org/10.5603/PMPI.2020.0002

Rodriguez, C., Ji, M., Wang, H.-L., Padhya, T., \& McMillan, S. C. (2019). Cancer Pain and Quality of Life. Journal of Hospice \& Palliative Nursing, 21(2). https://journals.lww.com/jhpn/Fulltext/2019/04000/Cancer_Pain_and_Quality_of_Life.4 .aspx

Shrestha, A., Martin, C., Burton, M., Walters, S., Collins, K., \& Wyld, L. (2019). Quality of life versus length of life considerations in cancer patients: A systematic literature review. Psycho-Oncology, 28(7), 1367-1380. https://doi.org/10.1002/pon.5054

Suprayitno, S; Prasetyo, DY; Untari, S. (2020). Kualitas hidup pasien kanker dalam menjalani kemoterapi. Jurnal Keperawatan, 12(4), 641-650.

Tang, F., Wang, J., Tang, Z., Kang, M., Deng, Q., \& Yu, J. (2016). Quality of life and its association with physical activity among different types of cancer survivors. PLoS ONE, 11(11), 1-13. https://doi.org/10.1371/journal.pone.0164971

WHO. (2000). Global cancer rates to rise by $50 \%$ by 2020. International Agency for Research on Cancer (IARC), 81(5), 385-386. 
Vol 3, No. 2, September 2018, pp.01-07

83

http://www.scielosp.org/scielo.php?script=sci_arttext\&pid=S0042-

$96862003000500022 \& \operatorname{lng}=$ en $\&$ nrm=iso\&tlng=en

YKI. (2017). Dalam Spirirt, Kita bisa, saya bisa. 